$10-2016$

\title{
The Legal Research Plan and the Research Log: An Examination of the Role of the Research Plan and Research Log in the Research Process
}

Caroline L. Osborne

West Virginia University College of Law, caroline.osborne@mail.wvu.edu

Follow this and additional works at: https://researchrepository.wvu.edu/law_faculty

Part of the Legal Education Commons, Legal Profession Commons, and the Legal Writing and Research Commons

\section{Custom Citation}

Caroline L. Osborne, The Legal Research Plan and the Research Log: An Examination of the Role of the Research Plan and Research Log in the Research Process, 35 Legal Reference Services Q. 179 (2016).

This Article is brought to you for free and open access by the WVU College of Law at The Research Repository @ WVU. It has been accepted for inclusion in Law Faculty Scholarship by an authorized administrator of The Research Repository@WVU. For more information, please contact ian.harmon@mail.wvu.edu. 


\title{
The Legal Research Plan and the Research Log: An Examination of the Role of the Research Plan and Research Log in the Research Process
}

\author{
Caroline L. Osborne*
}

Table of Contents

I. A legal Research Plan Defined ................................. 2

II. What Are the Elements of a Legal Research Plan? .......... 5

A. Summary of Legally Relevant Facts .......................... 5

B. Statement of the Legal Issue.................................... 6

C. Statement of Jurisdiction ....................................... 7

D. Identification of Useful Sources and the Order in Which They Are Accessed ....................................... 8

E. Identification of Search Terms ................................. 11

III. Benefits to Using a Legal Research Plan....................... 13

IV. Examples of Legal Research Plans................................. 17

V. Execution of Your Strategy and the Research Log or "Taking Good Notes" .......................................... 24

VI. Conclusion............................................................. 25

New associate exits the office of Senior Partner with a research assignment. He or she returns to his or her office, sits down at the keyboard, pulls up his or her favorite search engine and begins typing in keywords. This is the usual start to a research project by a novice researcher. This process may result in an answer; however, it is usually little more than an answer. The average attorney jumps into a research question without thinking. ${ }^{1} \quad$ This article discusses the basic elements of a legal

* Assistant Dean for Legal Information Services and Professor of Legal Research, Washington and Lee University School of Law.

1. "The average attorney will dive into research without thinking. Don't yield to this temptation. Spend the time to just sit and think about your case, to 
research plan, recommends designs of research plans and identifies the role of the research log in the research process.

\section{A legal Research Plan Defined}

In its most simplistic form a legal research plan is a strategy for finding information on an identified topic. Strategy is loosely defined as the planning or conducting of an operation. ${ }^{2}$ Development of a strategy maximizes efficiency and accuracy through a systematic approach to a problem rather than reliance on the luck of the researcher. ${ }^{3}$ There is no single correct form of strategy; however, a systematic approach to a research problem, rather than a shot in the dark, requires a process engaged in legal analysis: identification of the relevant facts, legal issues and controlling jurisdiction, creation of a list of potential search terms and a strategy that identifies and evaluates a list of potential sources, an understanding of what one hopes to find in a particular source, and an expectation of how one intends to locate information in a specific source (index, table of contents, popular names table, search query). Researchers may select from a variety of different strategies. The knowledge and expertise of the researcher and the nature of the query forms the basis for any strategy. Perhaps, it is easiest to define what does not qualify as a legal research plan. Immediately pulling up your favorite search engine and commencing to type upon receipt of a research project is not a plan and does not employ any analysis or strategy. It is an example of a shot in the dark. Unfortunately, this is often the most favored approach of the new attorney or law student.

Technically, a legal research plan need not be written. ${ }^{4}$ Experienced attorneys intimately familiar with an area of law and the available resources covering the area are often able to form a plan to a research question in their head. Such attorneys are the

know what question you should research." Duane Ostler, The Strength Is in the Research, 20 UTAH B.J. 42, 43 (2007).

2. The American Heritage Dictionary of the English Language 1273 (William Morris, ed. Houghton Mifflin New College ed. 1978).

3. Steven M. Barkan et al., Fundamentals of Legal Research 14 (9th ed. 2009).

4. But see Robert C. Berring \& Elizabeth A. Edinger, Finding the LaW 331 (12th ed. 2005). "Before beginning any research write down a research plan ... [It] is essential." Id. 
exception and their skill is honed and developed after years of specialization and practice and, yes, writing out their plan. Thus, the technical answer to the question is no-there is no requirement of a writing to have an organized plan reflecting the legal analysis of the problem and a strategy to locate authority. The better answer, however, is yes, the plan should be written. A written memorial of the plan may range from a brief strategy jotted on the back of an envelope to an elaborate and detailed outline. To be clear, written does not refer to handwritten. In the age of the computer, a typed memorial of the strategy is equally sufficient.

This begs another question-Is preparing a research plan a transitional skill for the newly minted associate and law student? The answer is both yes and no. The skilled attorney described above still uses and formulates an actual strategy or plan for attacking the problem. He or she simply has trained himself or herself to create the strategy internally. Thus, the concept of using a strategy and planning research is not transitory. The skilled attorney, who has trained himself or herself to strategize and think through the elements of a research plan, automatically employs a strategy. The process, at some point, becomes so ingrained that it is rote. This is the ultimate goal-for the process to become rote.

What does a research strategy or plan look like in practice? Consider what a strategy or plan might look like when representing Mary and Jen in a civil action against the store and the security guard in the matter described below.

Mary and Jen are shopping at Fifth Avenue in New York City one Saturday afternoon. It was their last stop on an all-day shopping extravaganza. Having had a successful shopping trip and making multiple purchases, between them they had numerous shopping bags. Finding a sale table of sweaters, Mary and Jen proceeded to the dressing rooms with a variety of colors and sizes. Mary decided to pass but Jen purchased two sweaters. Upon completion of Jen's purchase, they gathered their bags and exited the store only to have the security censor catch them at the door.

Store security immediately descended upon Mary and Jen preventing their exit from the store and asking permission to inspect their bags. Tired and ready for a cold drink they were less than pleased at being detained. They were even less pleased when the security guard requested that they accompany him to his office in the back of the store taking their bags into a separate room and locking them in his office. 
A "back of the envelope" legal research plan for this question might look like:

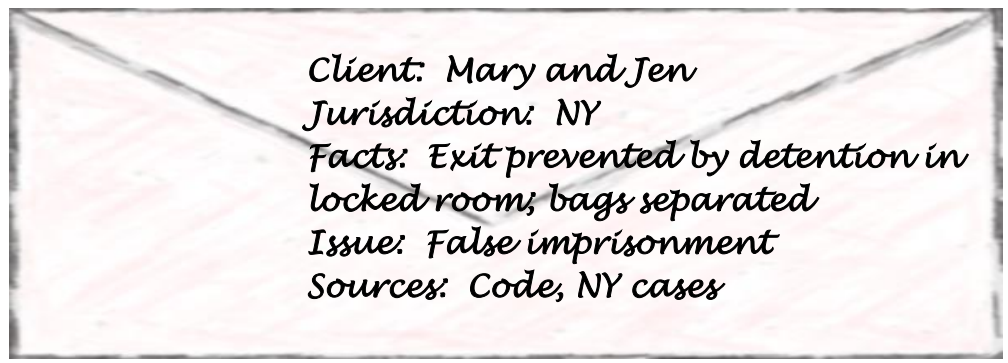

The amount of detail included in a plan depends upon the complexity of the issue and the knowledge and expertise of the researcher. A senior partner with forty years of expertise in an area usually will require a less detailed strategy than a first year associate with little substantive knowledge of the area of law. ${ }^{5}$ The complexity of the query also guides the level of detail required for a strategic approach to the question. ${ }^{6}$ A simple query such as, "Is Jones still the controlling authority on the issue of this intentional tort in my jurisdiction?" requires a far different approach than a research question involving a matter of first impression. Thus, the answer to the question of level of detail-is-it depends. The researcher must evaluate the complexity of the question and their knowledge of the substantive area of law to determine the appropriate strategy and amount of detail required. ${ }^{7}$

5. See generally Mark E. Wojcik, Ten Tips for Starting Your Research Right, 91 ILL. B.J. 359 (2003) "Although determining the parameters of a research assignment may be an obvious and easy step for seasoned attorneys, it can be tricky for new lawyers." Id.

6. Christina L. Kunz et al., The Process of Legal Research 25 (6th ed. 2004).

7. See also, Mark K. Osbeck, Impeccable Research: A Concise Guide to Mastering Legal Research Skills 6-7 (2010). "Consider the precise question presented and plan how you are to find the answer. For a simple project you might brainstorm a few minutes, jot down the question and sources of law you need. For a more complex project your plan might be more elaborate... The complexity of your plan will depend upon your comfort level and knowledge of the subject matter and time." Id. 


\section{What Are the Elements of a Legal Research Plan?}

A legal research plan or strategy is generally conceived to have five common elements: (1) identification of legally relevant facts both known and unknown; (2) statement of the legal issue or issues; (3) statement of jurisdiction; (4) identification of useful sources and the order in which they are to be used; and (5) identification of search terms. ${ }^{8}$

In addition to the generally recognized five common elements, also to be considered are the pragmatic factors such as the time allotted to the project, the final product to be produced and any limitation on use of resources. ${ }^{9}$ The fact that these are pragmatic considerations does not diminish their importance. Resources have a cost be it the cost to access Westlaw, Lexis Advance, or Bloomberg Law or the cost of a firm to purchase a print copy of the state code. The cost of the resource is a consideration in the same way an attorney or client places a value on the research project itself. Likewise, the real world places restrictions on access to resources. It is not unheard of for a client or firm to limit access to Westlaw or Lexis Advance. A well-conceived plan will acknowledge any such restrictions or concerns. An awareness of the client's desired result or endgame and the case of the opposition is also of significance in development of a strategy. It is not sufficient research to simply find the law that supports your client. A good lawyer understands and anticipates the opponent's case and is ready to address contrary authority.

\section{A. Summary of Legally Relevant Facts}

Not all facts are relevant and not all needed facts are known. Key to developing a successful strategic approach to a research

8. Berring \& Edinger, supra note 4, at 333. Berring suggests eight elements of a research plan: (1) deadline, (2) statement of time allocation, (3) amount of resources, (4) anticipated steps, (5) tools likely to be used, (6) search terms, (7) possible Boolean search terms, and (8) people. Id.

9. Berring \& Edinger, supra note 4, at 332. "How much is the question worth in terms of time and money? Not knowing this is a deal breaker. In the real world time is money and money is everything. (This is true in the public sector as well as the private.) One of the most frequent complaints made by senior lawyers about recent law school graduates is that they do not know how to budget time. To budget, you must know what is available. Therefore, the foundation question is how much time are you supposed to spend on the problem?" Id. 
question is to briefly summarize the facts provided. Weed through the facts provided to determine those that are relevant to the problem and identify any notable omissions. Often the researcher discovers facts needed but unknown. Consider the desired result of the client. Draft a timeline of the events. Identify each person involved and their place in the controversy. Evaluate the importance of each fact and what value or function is served. Develop a clear understanding of the factual predicate of your argument. Understanding the facts may suggest factual and legal research needed to support your argument and avoid embarrassment or legal malpractice. It also assists you in focusing your research.

\section{B. Statement of the Legal Issue}

This is often, alternatively, called formulation of the question presented. Simply put, this is the initial identification of the legal issue or issues to be researched. Correct identification of the legal issue is essential. It is common for a research question to have multiple issues or sub-issues. Formulation of a preliminary statement of the problem assists the researcher in defining the scope of the research problem. ${ }^{10}$ The act of constructing the hypothesis or issue statement usually requires some knowledge of the relevant law. ${ }^{11}$ Duane Ostler succinctly summaries this point_- "experienced researchers know that a careful evaluation of the question about to be researched may make the difference between average research findings, and those that will give you a winning argument."12

As the research process is undertaken, the researcher has the opportunity to refine the issue based on a new or better understanding of the problem. Framing the initial statement should not be confused with constructing the finely honed question presented for a brief or memo, but rather is a first draft of what will hopefully become the question presented. Questions to consider in the construction of the issue statement include: (1) is the matter one of civil or criminal law and (2) is the question a

10. Amy E. Sloan, Basic Legal Research ToOls ANd Strategies 307-08 (4th ed. 2009).

11. Barkan et al., supra note 3, at 16 .

12. Ostler, supra note 1 , at 43. 
matter of federal or state law. The benefit of writing out the issue statement in the form of a question presented is to focus work effort in the appropriate area. The researcher who struggles with the construction of the initial issue statement should step back and ask more questions about the scope of the assignment. ${ }^{13}$ One common definition of the formulation of the research issue is the combination of terms in the form of a question. ${ }^{14}$ Ask who, what, where, when, and why, the "w" questions, to aid in the development of the issue. Be cautious not to restrict your research so factually that you miss key authorities. Research the correct issue and do not be afraid to reconsider the initial question. What you find may impact how you view the initial issue statement and suggest refinement or change. In addition to the "w" questions, a formulation of the issue should consider the applicable legal theory, relief sought and procedural posture of the case. ${ }^{15}$ Last, but not least, a thorough understanding of the legal issues in combination with a carefully planned strategy is critical to maintain focus. ${ }^{16}$

\section{Statement of Jurisdiction}

The United States is composed of fifty plus jurisdictionsfederal, territorial and fifty separate and unique states. Given the importance of precedents in our system, identification of the relevant jurisdiction is necessary. It permits the researcher to focus his or her efforts to locate mandatory binding authority and otherwise evaluate authority. This step is imperative for any project and particularly projects with time and monetary constraints.

13. Sloan, supra note 10 , at 308 .

14. Kunz et al., supra note 6 , at 29.

15. Id. at 30-31; see also Berring \& Edinger, supra note 4, at 329. Berring suggests a different set of questions. "When embarking on a fresh search you should answer a list of questions. What is the exact topic of the search? Can it be refined? What is the context of the answer? Will a lawyer or a client use the information? Does the requesting party want an answer to a query or a set of alternatives? Does the source of the question want you to find a case, a statute, a regulation, some secondary authority or a relevant form? Is the problem a federal one or a state one? Without a full understanding of questions like these, no real progress can be made." Id.

16. Marsha L. Baum, Ten Tips for Moving Beyond the Brick Wall in the Legal Research Process, 10 Perspectives 20 (2001). 
Research is expensive. The attorney's time as well as the cost of accessing materials is a crucial factor. The goal of a research project is always to locate all relevant authority. This includes authority that supports your position as well as any that does not. Persuasive authority is often a luxury that cannot be afforded. Identification of the appropriate jurisdiction aids the researcher in identifying controlling from persuasive authority and restricts the universe of information.

Identification of the jurisdiction for the plan is usually a phrase. Is the issue federal, state or both? If federal, which circuit controls and what is the underlying federal district court? If state, which state and is the state divided into districts? A statement of jurisdiction will usually be simply stated along the lines of Federal, 4th Circuit, Western District, North Carolina. If there are multiple issues, be cautious to determine if there are state issues in addition to federal issues. You may have separate jurisdictions depending upon the issue.

\section{Identification of Useful Sources and the Order in Which They Are Accessed}

Once the issue and the jurisdiction are identified, the next step is to identify useful sources and order of intended use. The goal is to identify sources likely to contain relevant information. Listing the sources one believes will provide the authority sought and the order in which one plans to access them permits planning. ${ }^{17}$ Creation of such a list also assists in identifying materials that are not readily available and may have to be obtained from other libraries. ${ }^{18}$ A researcher looks for authority to support the argument to be made on behalf of the client. Questions of what types of authorities are sought, why the type of authority is helpful and where it may be located are central to this part of the plan. Start with what is known and determine what is missing. 19 Secondary sources are particularly effective in assisting in the understanding of the actual problem and the location of primary authorities. $^{20}$

17. Berring \& Edinger, supra note 4, at 332 .

18. Id.

19. Sloan, supra note 10 , at 308 .

20. Osbeck, supra note 7 , at 8 . 
Selection of a tool is, in part, determined by the complexity of the question and level of familiarity with the area of the law. ${ }^{21}$ Efficiency is also desired. The goal is to maximize the use of each potential tool available. Consider "the functions that the tool serves [and] how it is designed." 22 Evaluate tools in light of their structure, timeliness and availability of cross-references or interconnectedness. It is imperative to know how to correctly use a resource to maximize its potential. In an age where information is available instantly from the web, currentness of the information remains a concern. Always look to determine when the information was last updated or the web page modified. Copyright dates, pamphlets, pocket parts, and supplements provide similar information in the print world.

This portion of the plan is often the most fluid. Identification of initial sources frequently expands to include other sources, as material is located. It is a mistake to think the process is linear. Inherently the research process is circular. It involves finding information, making a judgment call with respect to such information and then refining your plan. It is usual to revisit areas of the plan or strategy as more is learned. One may add or delete search terms or entire issues as well as identify new issues, search terms and sources of interest. Headnotes, annotations, citations and the West Key Number hierarchy are all well-developed tools that assist in the location of additional authority from one authority. ${ }^{23}$

Always include the tools that update material found. The law is fluid and, as such, includes tools to update the information located. Pocket parts, updated or replacement pages, supplements, and citators are valuable tools not to be overlooked. Research is not complete until your primary authorities have been validated as good law.

The customary goal is to locate the controlling, commonly called binding or mandatory, primary authority. This requires locating the case, statute, rule or regulation addressing the issue

21. Cf. Berring \& Edinger, supra note 4, at 333-34. "Such familiarity should never lead to complacency ... new cases are being decided, new statutes enacted, new rules are appearing. New fact situations are pushing and pulling at the most settled of doctrines. . . The most common mistake . . in using any research tool is to use it blindly." Id.

22. Id. at 334 .

23. Sloan, supra note 10 , at 310 . 
from the relevant jurisdiction. Secondary authorities are useful tools to educate a researcher on a topic. They may assist in developing search terms and a basic understanding of the concept. Finding aids, citators, and secondary authorities all aid in the identification of primary authorities.

Persuasive authorities also assist in refining or buttressing an argument and more specifically in the instance of a case of first impression. Before one spends a client's time and money on locating persuasive authority consider the question of why. Is this a case of first impression (i.e. no governing rule exists in the jurisdiction)? Does your argument depend on use of an analogy to support your reasoning? Do you need to support your position with additional cases? ${ }^{24}$ Each is a valid reason to support the search for additional authority; however, always consider the pragmatic parameters of the project. Law school invites the all-encompassing or mega search for authority. The real world of practice includes fiscal and temporal constraints. The ultimate question to ask is does the client benefit from the time spent to locate persuasive authority? Last but not least, is the authority located correctly identified as persuasive rather than mandatory?

Today's research environment has a foot in both the print and online worlds. Complete, accurate, and efficient research generally requires use of both online and print. ${ }^{25}$ Include both print and online resources in the list of potential sources, subject to any restrictions placed on the project. Considerations as to what source to use should include (1) cost, ${ }^{26}$ (2) availability, (3) content and coverage, and (4) credibility or authenticity. Do not mistake the concept of a free resource as satisfying the concept of cost effective research. Your time is valuable and repeating a search originally done on Google in Westlaw or Lexis Advance when you could have simply done the search in Westlaw or Lexis Advance is by definition inefficient. Some find statutory research to be easier to conduct in print, especially when the research is historical. ${ }^{27}$

24. Id. at 311 .

25. Id. at 312 .

26. Berring \& Edinger, supra note 4, at 332. "One law librarian at a large firm in San Francisco reminds the attorneys working there that they shouldn't spend more than ten minutes in an electronic database (LEXIS, WESTLAW, even Google) looking for what they want, otherwise they are wasting too much time (and money)." Id.

27. See, 2011 ABA Legal Technology Survey Report V-35 (ABA Legal Technology Resource Center 2011)(State legislation/statutes rank as fifth in the 
Similarly, when there is an absence of knowledge or information, tables of contents and subject indexing are particularly useful. Likewise, projects involving broad legal concepts or general search terms lend themselves to print. ${ }^{28}$ It is also important to consider that not everything is available online. Databases, even the largest ones like Westlaw, Lexis, Bloomberg, and Hein Online have some limitation on content whether the most current or the oldest materials.

As previously mentioned, this section of the plan is often the most fluid. Start with listing the primary authorities you have or seek and the sources you anticipate using to locate them. Repeat the process for secondary authorities and, finally, identify those sources you will need to update and validate your research. Maintain a record of what is found with a brief citation and a summary. Many employ a research log to record their research. It is important to keep track of the information you find along the way; often information initially discarded becomes what is ultimately needed. Most legal authorities are connected to other authorities through annotations, cross-references, and footnotes or endnotes. The West Key Number system is prevalent throughout the West publishing system. This is another feature specifically designed to connect authorities on a topic. Shepards and KeyCite similarly serve to connect authorities through citation analysis. Researching is educational. As you learn more you are able to refine your issue statement and hone in on what you need.

\section{E. Identification of Search Terms}

"A research term is an expression of the concept you plan to research." 29 Identification of search terms is the last step in the creation of the research plan. Often this is the most difficult step. Consider the example of one first year class that when assigned an Americans With Disabilities Act question focusing on reasonable accommodation, considered appropriate searches and search terms as "torts w/10 negligence" and "disabilities" in U.S.C.C.A.N. Online searching is powerful and a staple of the modern lawyer, when used correctly. Effective searches are central to efficient

top five topics searched in print.)

28. Sloan, supra note 10 , at 314.

29. Kunz, et al., supra note 6 , at 29. 
research. This section of the plan assists the searcher in constructing a good search rather than merely throwing search words at the wall to see what sticks. Full text searching for all its attendant benefits also has detriments. Consider the instance in which the controlling case is not located because the search involved the word "cat" rather than "dog." Synonyms, truncated terms, and concepts are critical to good research. Generating a list of search terms should also consider phrases designed to locate legal concepts or theories. Often legal concepts are best located through phrases rather than words. ${ }^{30}$ Start with the basic terms and phrases then expand the list, vertically and horizontally, and by adding synonyms and antonyms. Christina Kunz advocates the hub and spokes practice to generate search terms. ${ }^{31}$ The hub and spoke concept identifies one search word or phrase as the hub, and then spins off additional words that relate to or are synonyms of the hub to expand the list. ${ }^{32}$ Lexis offers suggestions for similar search terms that can assist the stumped searcher. A good dictionary and thesaurus are also useful tools to consult when compiling a list. Words and Phrases is an under-utilized source available in print and on Westlaw. Familiarity with the topic is always helpful. Secondary sources are often overlooked as a resource to identify meaningful search terms. Consider the benefits of simply understanding how a concept is indexed. The index terms alone are valuable clues to jargon and vocabulary. "Legal tools are organized around concepts and jargon. If you do not know the buzz words, you may never be able to find anything." 33

Some may elect to take an additional step, that of actually writing out the intended search. This is particularly useful when using Boolean or terms and connectors searches. Even those using natural language search methodology may benefit from seeing the query prior to running the search. The value of writing out the search is in seeing it and considering exactly what you have instructed the computer to search. This simple conceptunderstanding what you have instructed the computer to dorequires some familiarity with how a database processes a search.

\footnotetext{
30. Id. at 28 .

31. Id. at 31 .

32. Id.

33. Berring \& Edinger, supra note 4, at 330.
} 
Awareness of a few simple principles, such as the fact that setting off an item or phrase by parentheses in a Boolean search, can alter the order of processing and direct the parentheses to be done first. Placing a phrase in quotation marks can also visually highlight a phrase or term you intend to be searched. Understanding when or is processed may preclude an unintended search. Consider the simple search of Mary Smith or Jane Jones or William Matthews. Presumably the intended search is to locate the names of "Mary Smith," "Jane Jones," and "William Matthews." As constructed, the search methodology searches first for or thus searching for smith or jane and jones or william first, producing a result set likely to lead to an unintended result. An alternative might be mary / 2 smith or jane $/ 2$ jones or william $/ 2$ matthews. The simple act of writing out the search and considering the intended result can highlight needed revisions.

\section{Benefits to Using a Legal Research Plan}

The classic example of a poorly planned and executed research project is illustrated below by the failed summer associate example. "Ben," a second year law student, received the project of researching the validity of an assignment of rents in the state of Georgia. He spent hours on Westlaw conducting search after search in the 'everything' search box locating a variety of cases. He proceeded to draft what on its face appeared to be a well-written memo. The first hint of trouble reared its head when the partner noticed the key case cited in the memo was recently overruled. Trouble increased when the partner received the Westlaw charges detailing numerous searches. ${ }^{34}$ Ben spent hours randomly conducting one search after another. He effectively was throwing things at the wall to see if anything stuck. The ending was not pretty. At the conclusion of the summer, Ben failed to receive an offer. The research was inefficient, incorrect, and incomplete. Had Ben planned his approach, he would have been prompted to update his research, employ fewer searches, view fewer documents, and spend less time.

34. At the point in time this instance occurred, Westlaw charged by the search rather than the document view. The change in pricing structure does not alter the concern. The research strategy was ineffective. Ben viewing multiple documents has a similar result, a large bill and a bad memo. 
Efficiency and accuracy are the identifiable benefits to creating and following a strategy, methodology or plan. Taking the time to create a plan and organize your thoughts increases both the efficiency of the search and the accuracy. Planning minimizes the risk that important authorities are missed. The old adage "time is money" is especially true for lawyers. Research is expensive. It takes time to do quality analysis and research and the rate for a billable hour is anything but cheap. Resources also have associated costs. This requires attorneys to be efficient and accurate. In Ben's case, he spent hours conducting search after search to locate relevant cases. He ultimately located cases that appeared to be relevant only to fail to update his research. Use of the 'everything' search box rather than Georgia cases or the failure to narrow his results is indicative of inefficiency and failure to think through the project. A research plan or strategy avoids the haphazard search that often misses important authorities and ensures that all the key sources necessary to locate relevant authorities are searched. The added bonus of planning a strategy is "confidence that your research is correct and complete." 35 Inefficiency results when a "clear understanding of the specific steps you should take to solve the problem" is lacking. ${ }^{36}$

Mark Herrmann notes in The Ten Most Common Mistaken Assumptions Made by New Lawyers, "most new lawyers begin their legal research by turning on a computer; [t] his is almost invariably wrong. When you work for me, do not begin your research with a computerized database unless I expressly tell you to do so." ${ }^{7}$ It is easy for the new attorney to want to jump into the project by immediately pulling up his or her favorite search engine and entering a key word. This is the opposite of efficient. The frequent refrain that-it takes time to create a strategy and that is a waste-misses the point. A serendipitous approach will ultimately cost more in both time and accuracy than the few minutes it takes to organize a planned approach to the project. ${ }^{38}$ An online search that returns a result in excess of 3,000, such as the example of the first year searching disabilities in U.S.C.C.A.N., is flawed on every

35. Sloan, supra note 10 , at 305 .

36. Osbeck, supra note 7 , at 3 .

37. Mark Herrmann, This is What I'm Thinking: A Dialogue Between Partner and Associate . . From the Partner. 25 LiTiG. 8, 64 (1998).

38. Michael D. Murray and Christy Hallam DeSanctis, Legal Research Methods 14, n. 1 (2009). 
level. This is the classic example of where the student would benefit from being trained in using a strategic approach.

Formulation of the issue or issues, identification of the key facts and the other basic questions asked in the formulation of a plan along with an assessment of the amount of time, the final product, jurisdiction, and uses of persuasive authority, all guide the researcher in focusing his or her efforts in the desired direction. This act of focusing, alone, increases efficiency. Consider the "quick" research question in which one is asked to locate and email to the senior partner the relevant statutory provision addressing time to file a worker's compensation claim. The partner wants an email copy of a specific state statute. Most likely the partner views this as a .2 billable hour event with the end product being receipt of the statute via email. Little more is required of the associate than to identify the jurisdiction, locate the correct statutory provision, update and validate that the provision is good law and email it. A brief plan or strategy formulates the question, suggests the source, includes the relevant updating materials and would most likely suggest an index or table of contents approach to this query. Taking the time to think and plan before one types is an increase in efficiency. Consider the alternative: immediately upon receipt of the project the associate logs on to a service, types in "worker's compensation" as their query and receives a large result to cull through. An hour later, still with no answer, the associate looks up at the assigning partner in the doorway holding a printout of the provision.

If efficiency and accuracy are increased in the quick research assignment, their value increases proportionately in the complex assignment. Consider the example of the associate assigned to write a short memo and spend no more than a day researching the question of the validity and enforceability of a choice of law clause in the context of a contract. A good basic research plan would identify the issue, as "Is a choice of law clause in a contract enforceable or valid in the State of X?" Jurisdiction, amount of time, and work product are clearly identified. The next question is whether the issue is one addressed by a statute or case law and what resources are available to provide the relevant statutes or cases and update or validate the law located. The associate might also want to consider if there is a relevant treatise, article, or other secondary source that might be of use and where that source can be found. A plan that (1) identifies the issue and jurisdiction, (2) 
notes the possible relevant state code sections, reporters or case sources, and (3) identifies state contract treatises, bar journals, and the journals from local law schools has a strategy that is likely to produce an answer in the allotted time. The associate who starts the project by logging into secondary resources in a service, running a search for enforceability of choice of law clauses, and wading through multiple result sets and searches wastes precious time and the client's money. Efficiency and accuracy are diminished.

Use of persuasive authorities benefits from a coherent strategy. The threshold question of what purpose does the use of persuasive authority serve in this context is necessary to avoid wasted time and expense. Persuasive authorities are valuable; however, they must be used in a manner that contributes value. Failure to identify an authority as persuasive and failure to understand what value the use of a persuasive item adds can detract from the overall product. In the choice of law example above, the question is jurisdiction specific. A string cite including opinions from numerous other jurisdictions in which choice of law clauses are enforceable contributes little to nothing to the question of-Is this clause enforceable in a specific jurisdiction? It is a waste of the attorney's time and the client's money to locate, read, and analyze multiple cases simply to provide a citation. Alternatively, if the end product is to produce a memo supporting a policy change, the citation to authorities in alternative jurisdictions becomes highly relevant. Thinking, planning, and strategizing places the researcher in the position to make the correct calls as to what sources to use and when to stop.

Identification of a starting and an ending point is yet another benefit and way to increase efficiency. Where to begin and end is a concern for any project. Analysis of the starting point should always begin with current knowledge_- "What do you know NOW?"39 Other factors to consider include the existing knowledge base of the researcher regarding the topic and what they are given.

If you know the area well, you will not have to look for authorities in as many places and you can zero in on the sources you know are likely to lead you directly to the answer. When you are familiar with the area, you will feel more confident when you think you have found the right answer... The

39. J.D.S. ARMstrong \& Christopher A. KnotT, Where the LAW Is: AN Introduction to AdVANCEd LEGAL RESEARCH 240 (3d ed. 2009). 
converse is true when you are less familiar with the area of law-you will need to look to more sources to find authorities and you may not be as confident when you are trying to decide whether you should stop your research. ${ }^{40}$

Knowing when to stop is influenced by factors such as repetitive findings of the same sources or the failure to locate anything. Both indicate a need to stop. The writing process is the greatest beneficiary of using a systematic approach to research. "Legal research informs legal writing and legal writing is meaningless without accurate content." ${ }^{1}$ This quote best summarizes the interconnection between research and writing. You research to know the law and develop a position, argument, and advice. You write to convey the law to another. Too often these are viewed as separate processes that fail to connect. This is a mistake. The processes are intertwined in the most basic sense. The attorney conceives the initial argument and then must locate the authorities to support that position. As he or she researches he or she refines the argument based on the actual law. The process is symbiotic: research, write, refine, write, and research until the final product is completed.

\section{Examples of Legal Research Plans}

The following are examples of different research plans. The concept of a plan is flexible and permits a researcher to adapt his or her style with the basic elements of a plan.

40. Murray \& Hallam, supra note 38, at 14.

41. Barkan, supra note 3 , at 14 


\section{Example 1}

Flow Chart Style

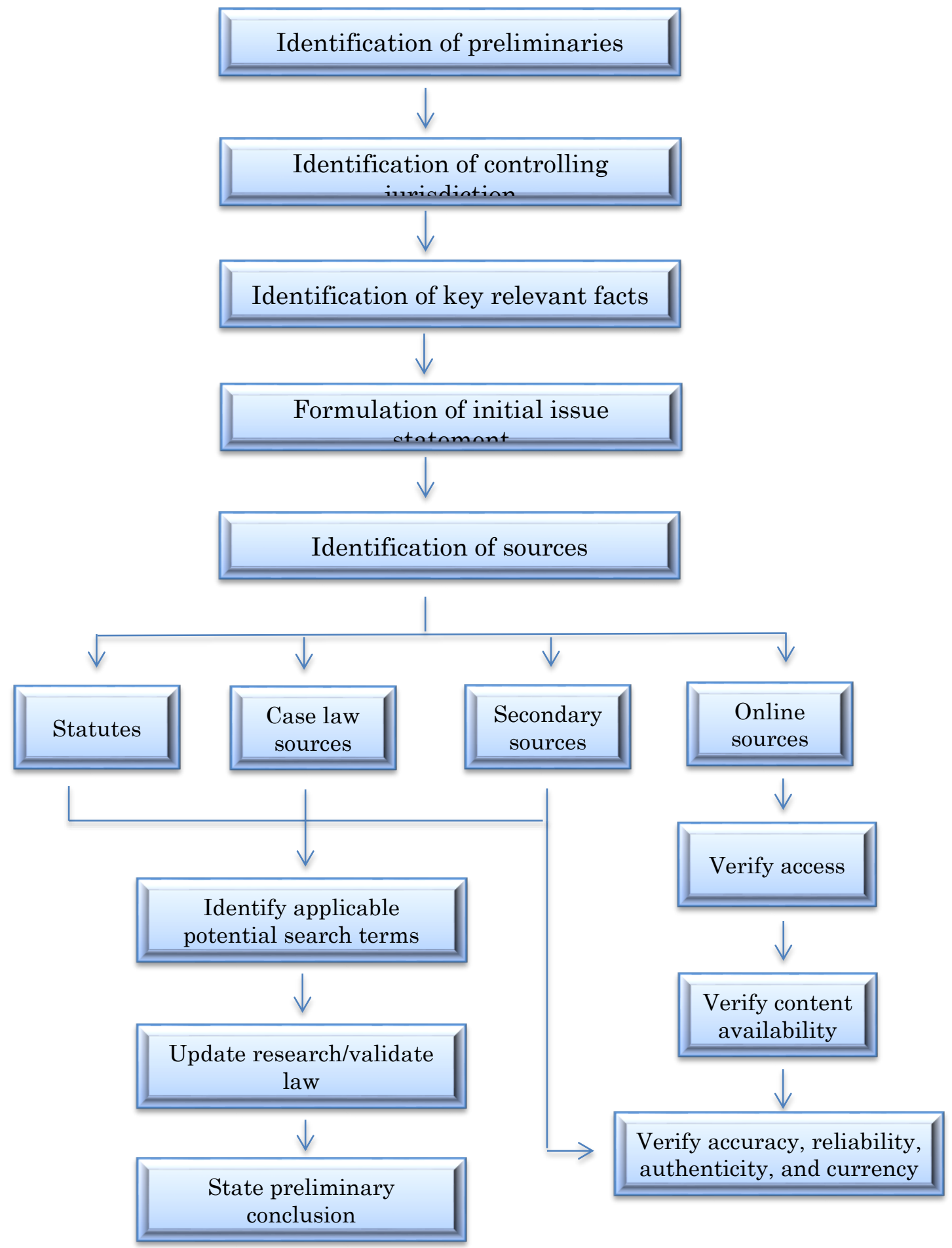




\section{Example 2}

\section{Checklist Style}

I. Preliminaries

$\square$ Due date

- Anticipated final product

- Restrictions on resources

II. Facts and issue statement

$\square$ Identify relevant facts

$\square \quad$ Identify needed facts

- Formulate initial statement of issue[s]

- State relevant jurisdiction

III. Sources and Terms

- Identify potential sources

$\square \quad$ Identify order to approach sources

$\square$ Generate list of search terms

- Identify citators and other sources required for updating research and validating law 


\section{Example 3}

Quick Version of Plan

I. Identify end product, time allocated, restrictions

II. Note relevant facts and formulate statement of issue

III. Identify relevant source and index terms

IV. Update research and validate law 
Example $4^{42}$

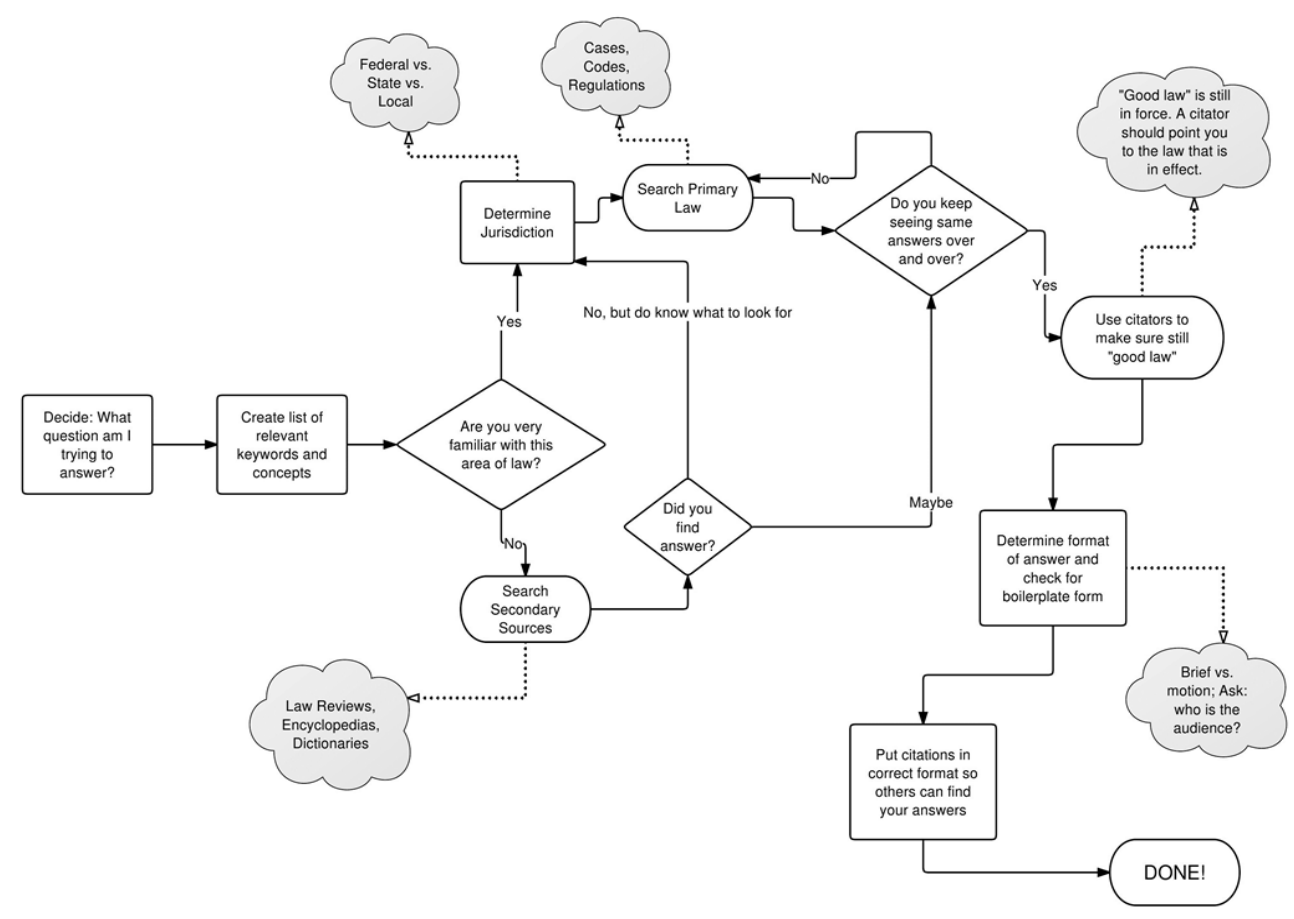

The Process of Legal Research

Christina L. Kunz et al., The Process of Legal Research 24 (6th ed. 2004).

42. Kunz, supra note 6, at 24 . 



\title{
Example 5
}

\author{
Westlâw. \\ Legal Research Project \\ Date Project Received: \\ Project Received From: \\ Project Due Date: \\ Client/Matter Number: \\ Requested Format for End Product (e-mail, memo, etc.): \\ Nature of Case or Issue (WEST Key Number):

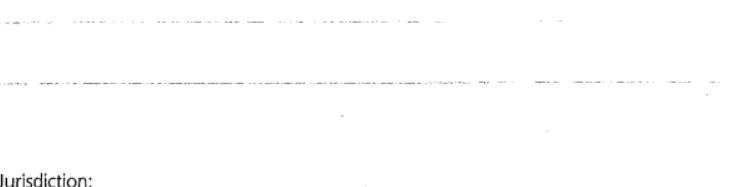 \\ West Reference Attorneys \\ 24 Hours a Day, 365 Days a Year | 800-REF-ATTY (800-733-2889) \\ Jurisdiction:

Key Terms:

Cost Restraints:

Amount of Time Allowed to Spend on Project:

Any Research Started on Project Already:

Any Experts in the Firm Who Can Help: 


\section{Execution of Your Strategy and the Research Log or "Taking Good Notes"}

Everything that precedes this section V constitutes the analysis and planning stage of the research process. The implementation of a strategy is the execution stage of the research plan. As briefly alluded to above, the researcher must take good notes in the execution phase of his or her strategy. The goal is finding the material that, hopefully, answers the question. Implementing the strategy and locating the cases, statutes, regulations, journal articles, treatises, and other materials that constitute the authority for the argument is the successful conclusion of the goal. Execution of a strategy is intertwined with the writing and research process. Failure to locate the anticipated information suggests it is time to revisit the strategy and revise as needed. As one composes the argument, he or she likely will find holes that need to be plugged, requiring additional research. For all these reasons it is helpful to maintain a record of your research efforts. Many use the folder system and the research trails available on Westlaw, Lexis Advance, and Bloomberg Law to fill this function. These are excellent tools but are limited to their systems. Note taking must be comprehensive.

The research log is one system many find useful in documenting their research progress. The research log is a comprehensive list of the sources searched and a summary of findings. The simplest construction of a log is in table format with the date you accessed the information, a cite to the source, location of the information, a brief summary of the information found, the currency of the information and the status of the information as good law. A research log might look like this table:

\begin{tabular}{|l|l|l|l|l|l|}
\hline $\begin{array}{l}\text { Date } \\
\text { accessed }\end{array}$ & Cite & $\begin{array}{l}\text { Where you } \\
\text { located the } \\
\text { information } \\
\text { /database }\end{array}$ & $\begin{array}{l}\text { Summary of } \\
\text { the } \\
\text { information } \\
\text { found }\end{array}$ & $\begin{array}{l}\text { Source date } \\
\text { /currentness }\end{array}$ & $\begin{array}{l}\text { Validity/ } \\
\text { Citator }\end{array}$ \\
\hline
\end{tabular}

A minimal amount of information is required to make the log useful when needed; however, the researcher may make the log as detailed a summary of the research process as desired. Types of information the researcher may consider include author, title, edition, year of publication, library call number, words and 
phrases, database name or identifier, names of institutions, societies, associations or agencies that focus on the area of interest, common authors or works on the subject, library of congress subject headings, notes about the information, date searched. Having this information available minimizes duplication and assists the researcher in determining that universe of sources on

point is exhausted. It also identifies vocabulary that is successful in locating relevant authority. ${ }^{43}$

\section{Conclusion}

The legal research plan is effective to create an efficient research strategy producing quality research. There is no single correct form of a legal research plan. Researchers may select from a variety of options and tailor the plan to fit their query and style of researching so long as they address the common elements of any plan. The common elements of any plan are fact identification, issue identification, jurisdiction, resource identification, and vocabulary. In addition to the common elements, preliminary considerations of time, end product, and restrictions are important to consider before beginning research. The research log is an effective tool to document the research process and maintain notes needed to construct an argument.

43. See generally Develop the Habit: Note TAKing in Legal Research, 4 Perspectives: Teaching Legal Res. \& Writing 48 (1996). 